Article

\title{
Changes in Intakes of Total and Added Sugar and their Contribution to Energy Intake in the U.S.
}

\section{Ock K. Chun ${ }^{1, *}$, Chin E. Chung ${ }^{2}$, Ying Wang ${ }^{1}$, Andrea Padgitt ${ }^{3}$ and Won O. Song ${ }^{3}$}

1 Department of Nutritional Sciences, University of Connecticut, Storrs, CT 06269, USA;

E-Mail: ying.3.wang@uconn.edu

2 Food and Nutrition, Ansan College, Ansan, Korea; E-Mail: cechung@ansan.ac.kr

3 Department of Food Science and Human Nutrition, Michigan State University, East Lansing, MI 48824, USA; E-Mails: ajpadgitt@juno.com (A.P.); song@msu.edu (W.O.S.)

* Author to whom correspondence should be addressed; E-Mail: ock.chun@uconn.edu; Tel.: 1-860-486-6275; Fax: 1-860-486-3674.

Received: 17 June 2010; in revised form: 28 July 2010 / Accepted: / 30 July 2010 /

Published: 3 August 2010

\begin{abstract}
This study was designed to document changes in total sugar intake and intake of added sugars, in the context of total energy intake and intake of nutrient categories, between the 1970s and the 1990s, and to identify major food sources contributing to those changes in intake. Data from the NHANES I and III were analyzed to obtain nationally representative information on food consumption for the civilian, non-institutionalized population of the U.S. from 1971 to 1994. In the past three decades, in addition to the increase in mean intakes of total energy, total sugar, added sugars, significant increases in the total intake of carbohydrates and the proportion of carbohydrates to the total energy intake were observed. The contribution of sugars to total carbohydrate intake decreased in both 1-18 y and 19+ y age subgroups, and the contribution of added sugars to the total energy intake did not change. Soft drinks/fluid milk/sugars and cakes, pastries, and pies remained the major food sources for intake of total sugar, total carbohydrates, and total energy during the past three decades. Carbonated soft drinks were the most significant sugar source across the entire three decades. Changes in sugar consumption over the past three decades may be a useful specific area of investigation in examining the effect of dietary patterns on chronic diseases.
\end{abstract}

Keywords: total sugar; added sugar; energy; diet; obesity 


\begin{abstract}
Abbreviations: National Health and Nutrition Examination Survey (NHANES); cardiovascular diseases (CVD); National Center for Health Statistics and the Centers for Disease Control and Prevention (NCHS/CDC); U.S. Food Supply Data (FSD); Continuing Survey of Food Intakes by Individuals (CSFII); high-fructose corn syrup (HFCS)
\end{abstract}

\title{
1. Introduction
}

Sugars are a ubiquitous component of our food supply. They are consumed as a naturally occurring component of our diet and as additions to foods during processing, preparation, or at the table. A healthy diet contains at least some amount of naturally occurring sugars, because monosaccharides, such as glucose and fructose, and disaccharides, such as sucrose and lactose, are integral components of fruit, vegetables, dairy products, and many grains [1]. Sugars also add desirable sensory effects and promote enjoyment of foods. Over the years, however, sugar intake has been claimed to be associated with several diet-related chronic diseases: diabetes, CVD, obesity, dental caries, and hyperactivity in children [2,3]. One of overwhelming concerns regarding sugars is the potential for excess energy intake from sugars resulting in weight gain and displacement of more nutrient-dense foods [2]. However, little attention has been given to the contribution of sugar and carbohydrates to total energy intake.

In explaining the relationship of certain nutrients or dietary patterns to chronic disease, it is important to examine not only the total intake of macronutrients and their components, but also their contribution to total energy intake. We have reported on the association between diabetes biomarkers and increased percent of energy intake from carbohydrates [4], and reported changes in U.S. children's beverage consumption patterns in the past decades [5]. However, previous studies on the trends of nutrient intakes in the U.S. [6-9] provided only limited evidence to help explain health impacts associated with consumption of simple and complex carbohydrates, with their ratios to total carbohydrate intake, and with changes in food supply and processing practices. Furthermore, these earlier studies utilized vastly different methodologies, complicating any effort to draw inferences about the relationship of sugar intake to health impacts [10].

Trends of sugar consumption in the U.S. have typically been calculated based on the per capita sugar consumption estimates reported annually by the Economic Research Service using the market disappearance data [11]. These per capita estimates, however, do not take account of differences between the amount purchased and the amount actually consumed. Therefore, it is important to use data on actual consumption, gathered utilizing relatively consistent survey and sampling methods to achieve representative results for the national population. Previous studies analyzing a series of NHANES data documented a steep increase in the prevalence of obesity from mid 1970s through 2000 [12], and a number of studies have shown a significant association between sugar and obesity, especially in children and adolescents [13-15]. Therefore, the objectives of this study were to determine trends in the U.S. population and age subgroups, from the 1970s to the 1990s, in total sugar intake and intake of added sugars, in their contribution to total energy intake, and in the food groups contributing principally to sugar and energy intakes. The data for the study were drawn from the 
National Health and Nutrition Examination Survey, NHANES, I and III (National Center for Health Statistics 1985; 1998).

\section{Methods}

\subsection{Characteristics of Datasets}

The NHANES I and III were conducted by the National Center for Health Statistics and the Centers for Disease Control and Prevention (NCHS/CDC) through interviews, questionnaires and examinations. The purpose of the surveys was to obtain nationally representative information on the health and nutritional status of the civilian, non-institutionalized population of the U.S. (NHANES I, 1971-1975; NHANES III, 1988-1994) [16-18]. Details of survey procedures, handling of samples and analytical procedures are described elsewhere [18]. The characteristics of the NHANES I and NHANES III data sets are shown in Table 1. Data for NHANES I were gathered from 20,195 participants, ages 1 to $74 \mathrm{y}$, and for NHANES III were gathered from 28,663 participants, ages 1 to 90 y. Subjects with unreliable and incomplete dietary recall records as coded by NCHS were excluded in this study. A listing of the 1,823 unique foods recorded during collection of the 24-hour dietary recall data in the NHANES I was matched to a corresponding food item listed in the NHANES III nutrient database by name and nutrient composition. Both criteria were used to determine the most suitable match for all 1,823 foods. An appropriate match could not be identified for 12 foods (Table 1).

\subsection{Study Design}

An individual's total sugar $\left(\mathrm{g} \cdot \mathrm{d}^{-1}\right)$ intake was calculated as the sum of glucose, fructose, galactose, sucrose, maltose, and lactose intakes. The definition of "added sugars" was taken from the National Cancer Institute [19]: white sugar, brown sugar, raw sugar, corn syrup, corn syrup solids, high fructose corn syrup, malt syrup, maple syrup, pancake syrup, fructose sweetener, liquid fructose, honey, molasses, anhydrous dextrose, crystal dextrose, saccharin, and aspartame that are eaten separately or used as ingredients in processed or prepared foods. Data of total and added sugars were not available in the NHANES I database. Thus intakes of these nutrients for NHANES I were estimated by matching food codes to those listed in the NHANES III food composition tables. U.S.D.A.'s 53 food categories were used to estimate the food sources of dietary sugar and other nutrients [20].

\subsection{Statistical Methods}

All data analyses were carried out using SAS, release 8.1 (SAS Institute Inc, Cary, NC, USA) and Survey Data Analysis for multi-stage sample designs professional software package (SUDAAN, release 8.01, Research Triangle Institute, Research Triangle Park, NC, USA) [21]. SUDAAN was used to increase the validity of the results by computing variance estimates and test statistics for a stratified, multistage probability survey design. Sample weights were applied to all analyses to account for the unequal probability of selection, non-coverage, and non-response bias resulting from over-sampling of low-income persons, adolescents, the elderly, African-Americans, and Hispanics. Means and standard errors for all nutrients examined were calculated using PROC DESCRIPT in SUDAAN. 
Table1. Characteristics of NHANES I and NHANES III datasets.

\begin{tabular}{|c|c|c|}
\hline & NHANES I (1971-1975) & NHANES III (1988-1994) \\
\hline Sample size & 20,195 & 28,663 \\
\hline Age range & $1-74 y$ & $1-90 y$ \\
\hline Individual food intake data & 353,664 & 430,050 \\
\hline $\begin{array}{l}\text { Number of individual foods } \\
\text { in the data set }\end{array}$ & 3,462 & 7,096 \\
\hline $\begin{array}{l}\text { Numbers of total sugar is } \\
\text { greater than } 0 \text { in NHANES III }\end{array}$ & - & 4,000 \\
\hline $\begin{array}{l}\text { Numbers of added sugar is } \\
\text { greater than } 0 \text { in NHANES III }\end{array}$ & - & 2,226 \\
\hline Number of consumed foods & 1,823 & 4,732 \\
\hline Number of non-matched foods & $12^{\mathrm{a}}$ & - \\
\hline Number of matched foods & 1,811 & - \\
\hline Nutrient variables in the dataset & $\begin{array}{l}\text { energy, protein, fat, carbohydrate, saturated fatty acid, } \\
\text { oleic acid, linoleic acid, cholesterol, vitamin A, } \\
\text { thiamin, riboflavin, niacin, vitamin C, calcium, } \\
\text { Phosphorus, iron, sodium, potassium }\end{array}$ & $\begin{array}{l}\text { energy, protein, fat, carbohydrate, saturated fatty acid, oleic acid, } \\
\text { linoleic acid, linolenic acid, monounsaturated fatty acid, polyunsaturated } \\
\text { fatty acid, cholesterol, fiber, alcohol, vitamin A, retinol, } \beta \text {-carotene, } \\
\text { tocopherol, thiamin, riboflavin, niacin, vitamin B6, vitamin B12, folate, } \\
\text { vitamin C, calcium, phosphorus, manganese, iron, sodium, potassium, } \\
\text { glucose, fructose, galactose, sucrose, lactose, maltose, sugar, added sugar }\end{array}$ \\
\hline $\begin{array}{l}\text { Matched variables with NHANES III } \\
\text { food composition table }\end{array}$ & $\begin{array}{l}\text { sugar, added sugar, fiber, } \beta \text {-carotene, folate, } \\
\text { vitamin } \mathrm{B} 6 \text {, vitamin } \mathrm{B} 12\end{array}$ & - \\
\hline
\end{tabular}

\footnotetext{
${ }^{a} 12$ food items in the individual food consumption data file of NHANES I could not be matched, because these items were not described in the food description file of NHANES I.
} 


\section{Results}

\subsection{Food Code Matches between NHANES I and NHANES III}

Estimates of the NHANES I subjects' nutrient intake levels generated by our food code matching technique (adopted from NHANES III) were comparable to those resulting from analysis of the original food codes of NHANES I. The values resulting from the food code matching technique and the analysis of the NHANES I data were, respectively: for total intake of food and beverages, 2,070 vs. $2,070 \mathrm{~g} \cdot \mathrm{d}^{-1}$; for total energy intake, $1,988 \mathrm{vs} .2,000 \mathrm{kcal} \cdot \mathrm{d}^{-1}$; for total carbohydrate intake, $224 \mathrm{vs}$. $236 \mathrm{~g} \cdot \mathrm{d}^{-1}$; and for percent of energy intake from fat, $36 \%$ vs. $36 \%$ (Table 2 ).

Since the original NHANES I database did not contain sugar intake data, some means of estimating those intakes had to be devised. Since nearly identical values were obtained for the four test nutrient variables from food code matching estimates and from analysis of the original NHANES I data, we felt confident in using the food code matching technique to estimate sugar intake levels for NHANES I participants.

\subsection{Changes in Sugar and Added Sugar Intake Levels from NHANES I to NHANES III}

Compared with NHANES I, the mean dietary intake levels in NHANES III were greater for total energy intake $\left(+144 \mathrm{kcal} \mathrm{d}^{-1} ;+7 \%\right)$, total sugar intake $\left(+10 \mathrm{~g} \mathrm{~d}^{-1} ;+8 \%\right)$, intake of added sugars $\left(+9 \mathrm{~g} \mathrm{~d}^{-1} ;+12 \%\right)$, and total carbohydrate intake $\left(+40 \mathrm{~g} \mathrm{~d}^{-1} ;+18 \%\right)$ (Table 3$)$. The results differed considerably by age subgroup. The change in mean total energy intake for participants ages 1 to 18 was lower by $3 \%$, whereas it was higher by $11 \%$ for participants ages $19+$ (Table 3 ). Mean total sugar intake and intake of added sugars increased for participants ages $1-18$ by $+0 \%$ and $+5 \%$, respectively, whereas the means for participants ages $19+$ increased by $+14 \%$ and $+18 \%$, respectively.

Table 2. Comparison of the mean nutrient intakes of the subjects in the NHANES I estimated based on the original and matched data.,

\begin{tabular}{lccc}
\hline Nutrient & $\begin{array}{c}\text { Means from original } \\
\text { data }^{\mathbf{c}}(\mathbf{N}=\mathbf{2 0 , 1 9 5})\end{array}$ & $\begin{array}{c}\text { Means from matched data } \\
\mathbf{( N = 2 0 , 1 9 5 )}\end{array}$ & $\begin{array}{l}\text { Difference }^{\mathbf{e}} \\
\mathbf{( \% )}\end{array}$ \\
\hline Energy $\left(\mathrm{kcal} \cdot \mathrm{d}^{-1}\right)$ & 1,988 & 2,000 & 1 \\
Carbohydrate $\left(\mathrm{g} \cdot \mathrm{d}^{-1}\right)$ & 224 & 236 & 5 \\
Protein $\left(\mathrm{g} \cdot \mathrm{d}^{-1}\right)$ & 79 & 76 & -4 \\
Fats $\left(\mathrm{g} \cdot \mathrm{d}^{-1}\right)$ & 82 & 81 & -1 \\
\%Energy from fats $(\%)$ & 36 & 36 & 0 \\
Saturated fatty acid $\left(\mathrm{g} \cdot \mathrm{d}^{-1}\right)$ & 30 & 31 & 3 \\
Cholesterol $\left(\mathrm{mg} \cdot \mathrm{d}^{-1}\right)$ & 372 & 329 & -12 \\
Calcium $\left(\mathrm{mg} \cdot \mathrm{d}^{-1}\right)$ & 856 & 858 & 0 \\
Iron $\left(\mathrm{mg} \cdot \mathrm{d}^{-1}\right)$ & 12 & 13 & 8 \\
Sodium $\left(\mathrm{mg} \cdot \mathrm{d}^{-1}\right)$ & 2,262 & 2,901 & 28 \\
Vitamin A $\left(\mathrm{I} \cdot \mathrm{U} \cdot \mathrm{d}^{-1}\right)$ & 4,728 & 4,783 & 1 \\
\hline
\end{tabular}


Table 2. Cont.

\begin{tabular}{llll}
\hline Thiamin $\left(\mathrm{mg} \cdot \mathrm{d}^{-1}\right)$ & 1.1 & 1.6 & 45 \\
Riboflavin $\left(\mathrm{mg} \cdot \mathrm{d}^{-1}\right)$ & 1.8 & 2.1 & 17 \\
Niacin $\left(\mathrm{mg} \cdot \mathrm{d}^{-1}\right)$ & 17 & 20 & 18 \\
Vitamin $\mathrm{C}\left(\mathrm{mg} \cdot \mathrm{d}^{-1}\right)$ & 85 & 90 & 6 \\
Phosphorus $\left(\mathrm{mg} \cdot \mathrm{d}^{-1}\right)$ & 1,253 & 1,225 & -2 \\
Potassium $\left(\mathrm{mg} \cdot \mathrm{d}^{-1}\right)$ & 2,325 & 2,627 & 13 \\
Total grams of food or & 2,070 & 2,070 & 0 \\
beverage $\left(\mathrm{g} \cdot \mathrm{d}^{-1}\right)$ & & \\
\hline
\end{tabular}

${ }^{\text {a }}$ Sample includes those with reliable and complete dietary interview data.

${ }^{\mathrm{b}}$ Means are sample-weighted.

${ }^{\mathrm{c}}$ Nutrient intakes were calculated from original data of NHANES I (1971-1975).

${ }^{d}$ Nutrient intakes were estimated by NHANES III food composition table through matching food codes of NHANES I to NHANES III.

${ }^{\mathrm{e}}$ Percent differences of matched means compared with original means.

\subsection{Sources of Energy and Sugars in the U.S. Diets}

Appendix A shows the changes in major contributing food items, from NHANES I to NHANES III, for participants ages 1-18 y. Major contributing food items for total energy intake changed (in descending order of importance) from fluid milk/breads/meats to mixtures of mainly grain/fluid milk/breads. Major contributing food items for total carbohydrate intake changed from breads/fluid milk/carbonated soft drinks to carbonated soft drinks/mixtures of grain/breads. Major contributing food items for total sugar intake changed from fluid milk/carbonated soft drinks/cakes, pastries, pies to carbonated soft drinks/ fluid milk/fruitades and drinks. Major contributing food items for intake of added sugars changed from carbonated soft drink/candies, sweets/cakes, pastries, pies to carbonated soft drinks/fruitades and drinks/candies, sweets.

Appendix B shows the changes in major contributing food items for adult participants (age 19+ y) for the same period. Major contributing food items for total energy intake changed from meats/breads/fluid milk to mixtures of mainly grain/breads/mixed meat dishes. Major contributing food items for total carbohydrate intake changed from breads/carbonated soft drinks/cakes, pastries, pies to breads/carbonated soft drinks/mixtures of grain. Major contributing food items for total sugar intake changed from carbonated soft drinks/fluid milk/sugars to carbonated soft drinks/cakes, pastries, pies/fluid milk. Major contributing food items for intake of added sugars changed from carbonated soft drinks/sugars/cakes, pastries, pies to carbonated soft drinks/cakes, pastries, pies/sugars.

The most salient feature of the changes in food items contributing to total energy intake is the rise of "mixtures of mainly grain" from relatively insignificant to the most significant contributor in both age subgroups. This food item includes mixtures having a grain product as a main ingredient, such as burritos, tacos, pizza, egg rolls, quiche, spaghetti with sauce, rice and pasta mixtures; frozen meals in which the main course is a grain mixture; noodle and rice soups; and baby-food macaroni and spaghetti mixtures [20]. 
Table 3. Comparison of the mean daily nutrient intakes between the NHANES I (1971-75) and NHANES III (1988-94)., b

\begin{tabular}{|c|c|c|c|c|c|c|c|c|c|}
\hline \multirow[b]{2}{*}{ Nutrient } & \multicolumn{3}{|c|}{ All age } & \multicolumn{3}{|c|}{$\underline{1-18 y}$} & \multicolumn{3}{|c|}{$\underline{19+y}$} \\
\hline & $\begin{array}{l}\text { NHANES I } \\
\mathrm{n}=20,195\end{array}$ & $\begin{array}{l}\text { NHANES III } \\
\mathrm{n}=28,663\end{array}$ & $\begin{array}{c}\text { Mean } \\
\text { difference }^{\mathrm{c}}(\%)\end{array}$ & $\begin{array}{l}\text { NHANES I } \\
\mathrm{n}=7,090\end{array}$ & $\begin{array}{l}\text { NHANES III } \\
\mathrm{n}=12,715\end{array}$ & $\begin{array}{c}\text { Mean } \\
\text { difference (\%) }\end{array}$ & $\begin{array}{l}\text { NHANES I } \\
\mathrm{n}=13,105\end{array}$ & $\begin{array}{c}\text { NHANES III } \\
\mathrm{n}=48,159\end{array}$ & $\begin{array}{c}\text { Mean } \\
\text { difference (\%) }\end{array}$ \\
\hline Total sugar $\left(\mathrm{g} \cdot \mathrm{d}^{-1}\right)^{\mathrm{d}, \mathrm{e}}$ & 120 & 130 & 8 & 138 & 139 & 0 & 110 & 126 & 14 \\
\hline Added sugar $\left(\mathrm{g} \cdot \mathrm{d}^{-1}\right)^{\mathrm{e}, \mathrm{f}}$ & 77 & 86 & 12 & 88 & 92 & 5 & 71 & 84 & 18 \\
\hline Calories $\left(\mathrm{kcal} \cdot \mathrm{d}^{-1}\right)$ & 1,988 & 2,132 & 7 & 2,018 & 1,962 & -3 & 1,972 & 2,198 & 11 \\
\hline Total fats $\left(g \cdot d^{-1}\right)$ & 82 & 82 & 0 & 83 & 75 & -10 & 81 & 85 & 5 \\
\hline Percent energy from total fat (\%) & 36 & 34 & -6 & 37 & 34 & -8 & 36 & 34 & -6 \\
\hline Saturated fatty acid $\left(\mathrm{g} \cdot \mathrm{d}^{-1}\right)$ & 30 & 29 & -3 & 32 & 28 & -13 & 30 & 29 & -3 \\
\hline Cholesterol $\left(\mathrm{g} \cdot \mathrm{d}^{-1}\right)$ & 372 & 269 & -28 & 328 & 225 & -32 & 396 & 286 & -28 \\
\hline Total carbohydrates $\left(\mathrm{g} \cdot \mathrm{d}^{-1}\right)$ & 224 & 264 & 18 & 244 & 259 & 6 & 213 & 266 & 25 \\
\hline Dietary fiber $\left(\mathrm{g} \cdot \mathrm{d}^{-1}\right)^{\mathrm{e}}$ & 13 & 16 & 19 & 13 & 13 & 0 & 14 & 17 & 25 \\
\hline $\operatorname{Protein}\left(\mathrm{g} \cdot \mathrm{d}^{-1}\right)$ & 79 & 78 & -1 & 76 & 68 & -11 & 80 & 82 & 2 \\
\hline Calcium $\left(\mathrm{mg} \cdot \mathrm{d}^{-1}\right)$ & 856 & 837 & -2 & 1,043 & 908 & -13 & 755 & 810 & 7 \\
\hline $\operatorname{Iron}\left(\mathrm{mg} \cdot \mathrm{d}^{-1}\right)$ & 12 & 15 & 29 & 11 & 14 & 33 & 12 & 16 & 26 \\
\hline Total vitamin $\mathrm{A}\left(\mathrm{IU} \cdot \mathrm{d}^{-1}\right)$ & 4,728 & 5,916 & 25 & 4,187 & 4,565 & 9 & 5,021 & 6,438 & 28 \\
\hline Beta Carotene $\left(\mu \mathrm{g} \cdot \mathrm{d}^{-1}\right)^{\mathrm{e}}$ & 1,929 & 2,535 & 31 & 1,614 & 1,694 & 5 & 2,100 & 2,860 & 36 \\
\hline Folate $\left(\mu \mathrm{g} \cdot \mathrm{d}^{-1}\right)^{\mathrm{e}}$ & 234 & 265 & 14 & 242 & 238 & -1 & 229 & 275 & 20 \\
\hline Vitamin B-6 $\left(\mathrm{mg} \cdot \mathrm{d}^{-1}\right)^{\mathrm{e}}$ & 1.6 & 1.8 & 13 & 1.5 & 1.6 & 3 & 1.6 & 1.9 & 17 \\
\hline Vitamin B-12 $\left(\mu \mathrm{g} \cdot \mathrm{d}^{-1}\right)^{\mathrm{e}}$ & 5.3 & 5.3 & 0 & 4.9 & 4.4 & -10 & 5.5 & 5.6 & 2 \\
\hline Thiamine $\left(\mathrm{mg} \cdot \mathrm{d}^{-1}\right)$ & 1.1 & 1.7 & 57 & 1.1 & 1.7 & 48 & 1.1 & 1.8 & 61 \\
\hline Riboflavin $\left(\mathrm{mg} \cdot \mathrm{d}^{-1}\right)$ & 1.8 & 2.0 & 14 & 2.0 & 2.0 & 4 & 1.7 & 2.0 & 20 \\
\hline Vitamin $\mathrm{C}\left(\mathrm{mg} \cdot \mathrm{d}^{-1}\right)$ & 85 & 90 & 5 & 83 & 89 & 7 & 87 & 91 & 5 \\
\hline Total grams of food or beverage $\left(\mathrm{g} \cdot \mathrm{d}^{-1}\right)$ & 2,070 & 2,289 & 11 & 1,722 & 1,718 & 0 & 2,259 & 2,510 & 11 \\
\hline
\end{tabular}

${ }^{a}$ Sample includes those with reliable and complete dietary interview data. ${ }^{b}$ Means are sample-weighted. ${ }^{c}$ Percent differences of means of NHANESIII compared with NHANES I. ${ }^{d}$ Total sugar is the sum of total glucose, fructose, galactose, sucrose, lactose, and maltose intakes. ${ }^{\mathrm{e}}$ Intakes of total sugar, added sugar, fiber, beta carotene, folate, vitamin B6, and vitamin B12 in NHANES I were estimated by NHANESIII food composition table through matching food codes of NHANES I to NHANES III. ${ }^{\mathrm{f}}$ One teaspoon of added sugars is converted to the quantity of a sweetener that contains the same amount of carbohydrate as $4.1 \mathrm{~g}$ of table sugar. 
Table 4. Comparisons of food items which contribute to nutrient intake between the NHANES I and III by age subgroups.

\begin{tabular}{|c|c|c|c|c|c|c|c|c|}
\hline \multirow{2}{*}{$\begin{array}{l}\text { Age } \\
\text { Survey }\end{array}$} & \multicolumn{4}{|c|}{$1-18 \mathrm{y}$} & \multicolumn{4}{|c|}{$19+\mathrm{y}$} \\
\hline & NHANES I & & NHANES III & & NHANES I & & NHANES III & \\
\hline \multirow{5}{*}{$\begin{array}{l}\text { Energy } \\
\left(\mathrm{kcal} \mathrm{d}^{-1}\right)\end{array}$} & Fluid milk & 321 & Mixtures of mainly grain & 230 & Meats (beef, pork, lamb, veal) & 236 & Mixtures of mainly grain & 175 \\
\hline & Yeast breads and rolls & 193 & Fluid milk & 155 & Yeast breads and rolls & 204 & Yeast breads and rolls & 170 \\
\hline & Meats (beef, pork, lamb, veal) & 150 & Yeast breads and rolls & 129 & Fluid milk & 156 & Mixtures mainly meat, poultry, fish & 151 \\
\hline & Potatoes & 105 & Regular carbonated soft drinks & 105 & Cakes, pastries, pies & 104 & Meat (beef, pork, lamb, veal) & 123 \\
\hline & Cakes, pastries, pies & 98 & Potatoes & 100 & Fats and oils & 95 & Cakes, pastries, pies & 110 \\
\hline \multirow{5}{*}{$\begin{array}{l}\text { Carbohydrate } \\
\left(\mathrm{g} \mathrm{d}^{-1}\right)\end{array}$} & Yeast breads and rolls & 36 & Regular carbonated soft drink & 27 & Yeast breads and rolls & 38 & Yeast breads and rolls & 31 \\
\hline & Fluid milk & 26 & Mixtures of mainly grain & 25 & Regular carbonated soft drink & 16 & Regular carbonated soft drink & 27 \\
\hline & Regular carbonated soft drink & 18 & Yeast breads and rolls & 23 & Cakes, pastries, pies & 15 & Mixtures of mainly grain & 18 \\
\hline & Cakes, pastries, pies & 15 & RTE cereals & 16 & Potatoes & 13 & Potatoes & 15 \\
\hline & Potatoes & 14 & Fluid milk & 14 & Fluid milk & 13 & Cakes, pastries, pies & 15 \\
\hline \multirow{5}{*}{$\begin{array}{l}\text { Total sugar } \\
\left(\mathrm{g} \mathrm{d}^{-1}\right)\end{array}$} & Fluid milk & 25 & Regular carbonated soft drink & 27 & Regular carbonated soft drink & 17 & Regular carbonated soft drink & 27 \\
\hline & Regular carbonated soft drink & 18 & Fluid milk & 14 & Fluid milk & 13 & Cakes, pastries, pies & 9 \\
\hline & Cakes, pastries, pies & 13 & Regular fruitades and drinks & 11 & Sugar and sugar substitutes & 12 & Fluid milk & 8 \\
\hline & Regular fruitades and drinks & 9 & Candies, sweets & 9 & Cakes, pastries, pies & 11 & Tea & 6 \\
\hline & Candies, sweets & 8 & Cakes, pastries, pies & 8 & Citrus juices & 6 & Regular fruitades and drinks & 6 \\
\hline \multirow{5}{*}{$\begin{array}{l}\text { Added sugar } \\
\left(\mathrm{g} \mathrm{d}^{-1}\right)\end{array}$} & Regular carbonated soft drink & 18 & Regular carbonated soft drink & 27 & Regular carbonated soft drink & 17 & Regular carbonated soft drink & 27 \\
\hline & Candies, sweets & 9 & Regular fruitades and drinks & 10 & Sugar and sugar substitutes & 12 & Cakes, pastries, pies & 7 \\
\hline & Cakes, pastries, pies & 9 & Candies, sweets & 9 & Cakes, pastries, pies & 8 & Sugar and sugar substitutes & 6 \\
\hline & Regular fruitades and drinks & 9 & Syrups, jellies and desserts & 6 & Syrups, jellies and desserts & 5 & Regular fruitades and drinks & 6 \\
\hline & Sugar and sugar substitutes & 6 & Cakes, pastries, pies & 6 & Yeast breads and rolls & 4 & Candies, sweets & 5 \\
\hline
\end{tabular}


The major food groups contributing to total sugar intake and intake of added sugars have remained carbonated soft drinks/fluid milk/sugars, cakes, pastries, and pies. Soft drinks were identified as the most significant source of added sugars, contributing $27 \mathrm{~g}$ of sugar intakes daily in NHANES III. The percentage of total sugar intake from soft drinks significantly increased by $49 \%$ and $39 \%$ for ages $1-18$ and $19+$, respectively, from NHANES I to NHANES III. In contrast, total sugar intake from milk and milk products dropped by $44 \%$ in 1-18 y subjects and $46 \%$ in $19+$ y subjects, respectively, during the same time period. Sugar intake levels from cookies and breakfast grains remained relatively the same during this time period (Table 4).

\subsection{Contribution of Individual Sugars to Total Sugar Intakes}

There were differences in the two time periods in the relative contribution of major food groups to average intakes of individual sugars, as a consequence both of changes in food processing and changes in food preferences [22,23]. Carbonated soft drinks, however, remained the greatest contributor to glucose and fructose intakes in all age groups, and fluid milk remained the principal source for lactose intake (Appendices A and B). Cakes, pastries and pies remained the principal source for sucrose intake in the 1-18 y age subgroup. Contribution of glucose and fructose to total sugar intake increased from $17 \%$ to $22 \%$ (23.4 to $30.7 \mathrm{~g} \cdot \mathrm{d}^{-1}$ ) and $16 \%$ to $21 \%$ (22 to $\left.27 \mathrm{~g} \cdot \mathrm{d}^{-1}\right)$, respectively, for $1-18 \mathrm{y}$ old subjects and $18 \%$ to $22 \%$ (20.3 to $\left.27.9 \mathrm{~g} \cdot \mathrm{d}^{-1}\right)$ and $18 \%$ to $21 \%\left(21.7\right.$ to $\left.29.7 \mathrm{~g} \cdot \mathrm{d}^{-1}\right)$ for over $19 \mathrm{y}$ old subjects, respectively. Lactose intake has deceased for three decades owing to the decrease in milk consumption and the contribution of lactose to total sugar intake decreased from $22 \%$ to $16 \%\left(30.9\right.$ to $21.6 \mathrm{~g} \cdot \mathrm{d}^{-1}$ ) for $1-18 \mathrm{y}$ old subjects and from $16 \%$ to $11 \%\left(17.3\right.$ to $\left.14.2 \mathrm{~g} \cdot \mathrm{d}^{-1}\right)$ for over $19 \mathrm{y}$ old subjects, respectively (Figure 1).

Figure 1. Comparison of the contribution (\%) of individual sugars* to the total sugar intakes between the NHANES I and III by age subgroups.

1-18 year old

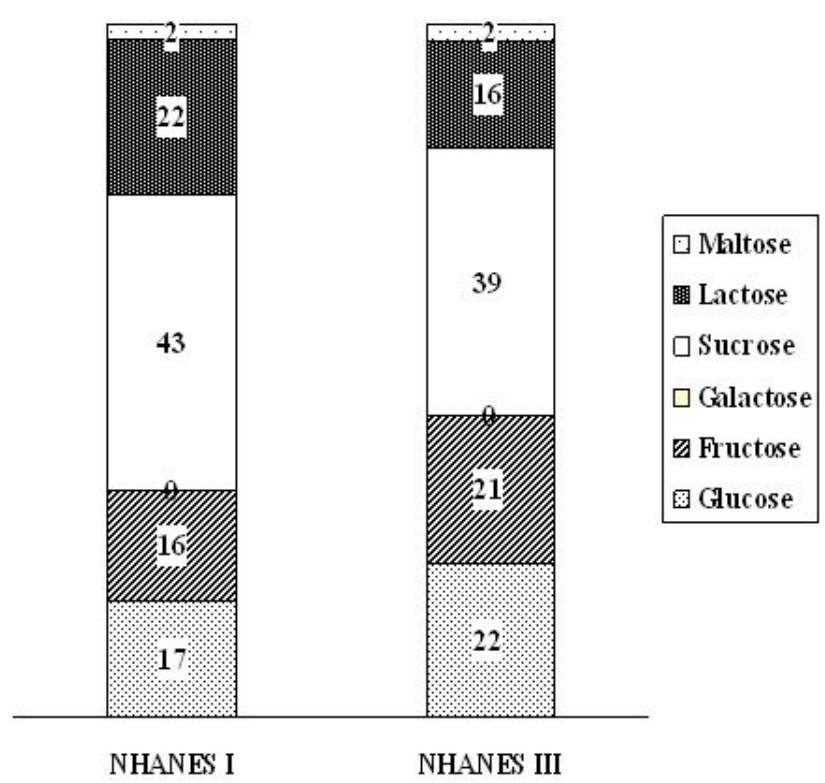

$19+$ years old

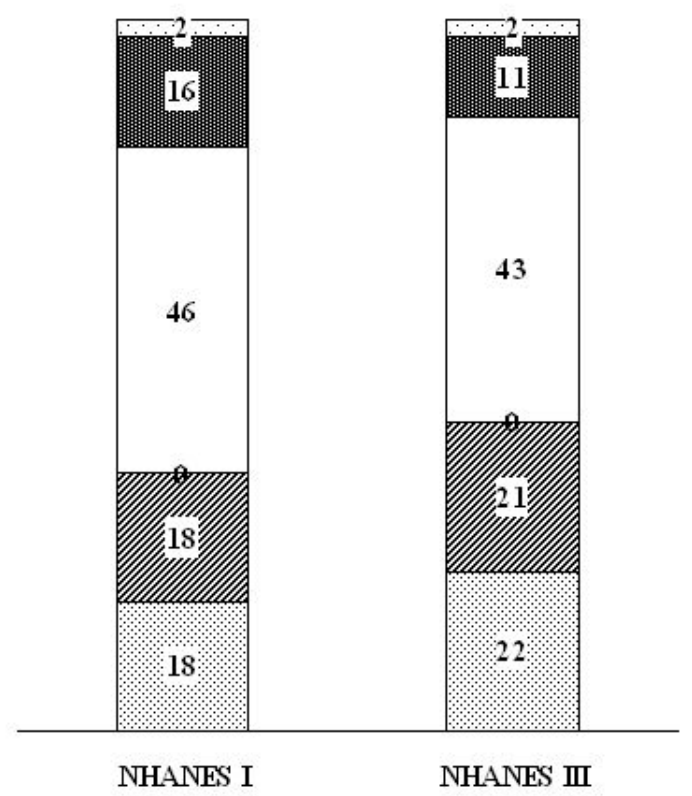

* Sum of fructose does not include metabolized fructose from sucrose. 


\section{Discussion}

Research findings on the assessment of added sugar intake in the U.S. population have been based on two main sources of data: the U.S. Food Supply Data (FSD) series [24] and the Continuing Survey of Food Intakes by Individuals (CSFII) [25,26], both products of the USDA. The Food Supply Series tracks the quantities of foods that flow through the food marketing system.

The FSD estimates are made at the commodity level. As a result, the data can be used to track changes in the total volumes (and population averages) of specific wholesale products (cane sugar, beet sugar, the various corn sweeteners) that contribute to sugar intake, and categories of their uses (as in beverages and baked goods, for example) [27]. However, since there are losses to domestic use by individual consumers through both waste at various stages of processing, and export, use of these data for population averages requires adjustment of the estimates to account for these losses. The resulting data is therefore less exact than could be hoped for [24]. The CSFII, which has been considered an ideal metric for the concept of added sugars in both Dietary Guidelines and the Food Guide Pyramid [27], provides data on food and nutrient intakes during only 1988-1991, 1994-1996 and 1998. Since 2002, this nationwide dietary intake database has been integrated with NHANES and the data collected as part of NHANES on a yearly basis. The NHANES databases provide a superior longitudinal data source, since they contain earlier data than the CSFII and have a longer period of continuity.

The Institute of Medicine [28] reported that people whose diets are high in added sugars have lower intakes of essential nutrients $(\mathrm{Ca}, \mathrm{Mg}, \mathrm{Mg}, \mathrm{Fe}, \mathrm{Zn}$, vitamin $\mathrm{A}$ and $\mathrm{E})$. It further suggests that added sugars should comprise no more than 25 percent of total calories consumed. In the present study, contribution of each macronutrient to the increased total energy intake was taken into consideration. We observed a significant increase in the total intake of carbohydrates (224 to $264 \mathrm{~g} \cdot \mathrm{d}^{-1}$ ) and the ratio of carbohydrates to the total energy intake (45 to 50\%), while the contribution of sugars to total carbohydrate intake has decreased in both $1-18$ y (57 to 54\%) and 19+ y (52 to 47\%) (Figure 2); while the contribution of added sugars to the total energy intake has not changed. These findings point to the need for more research into the particular nutritional components related to specific health concerns.

Several recent studies have suggested total sugar intake and intake of added sugars in the U.S. is related to the development of chronic diseases [26]. Some of these studies in particular identify carbonated soft drinks as a major contributor to energy intake and body weight gain [13-15]. Harnack et al. [29] reported that children's soft drink consumption had increased during the past three decades by providing $188 \mathrm{kcal} \cdot \mathrm{d}^{-1}$ extra energy to soft drink consumers beyond that to nonconsumers [29]. St-Onge [15] further suggested that these changes in food intakes among children may partly explain the rise in childhood obesity in the past few years. Adolescents consuming high sugar diets are also reported to be at increased risk for poor health [30] and consumption of sugar-added beverages may contribute to weight gain among adolescents probably due to their contribution to total energy intake [13].

The present study shows that energy intake in the 1-18 y subgroup actually decreased during the past three decades, unlike the increase of energy intake among 19+ y age subgroup. In addition, the percentages of energy intake from total carbohydrates increased by $4 \%$ and $5 \%$ in the $1-18$ y and $19+$ y age subgroups, respectively, while those from added sugar intake increased by only $1 \%$ in both age 
subgroups. Therefore, even though current trends in health promotion emphasize the importance of increasing carbohydrate intake and reducing fat intake (particularly saturated fat intake), concern has focused on sugar consumption from soft drinks as a main contributor to total energy intake.

Consumption of added sugars in the U.S. has increased steadily as documented by both FSD and nationwide food consumption survey data. According to U.S. FSD, per capita consumption of added sugars by Americans went from $111 \mathrm{~g} \cdot \mathrm{d}^{-1}$ in 1970 to $131 \mathrm{~g} \mathrm{~d}^{-1}$ in 1996, an increase of $23 \%$ [24]. These data are adjusted for spoilage, other losses accumulated throughout the marketing system and home waste losses. Food consumption survey data also demonstrate an increase in intake of added sugars. According to the USDA CSFII of Americans over 2 y old, consumption of added sugars rose from $64 \mathrm{~g} \cdot \mathrm{d}^{-1}$ in $1989-1991$ to $84 \mathrm{~g} \cdot \mathrm{d}^{-1}$ in $1994-1996$, an increase of $31 \%$ in less than ten years. In 1989 1991, added sugars accounted for $13.2 \%$ of total daily energy intake, whereas in 1994-1996 they accounted for $15.8 \%$ [27]. Although the data from each source indicate an increase in the consumption of added sugars, these increases have not previously been considered in the context of overall changes in macronutrient contribution to total energy intake. Data in the present study confirm the increase in intake of added sugars found in earlier studies, but while the increase in the intake of added sugars during the past three decades was $12 \%\left(77 \mathrm{~g} \cdot \mathrm{d}^{-1}\right.$ to $\left.86 \mathrm{~g} \cdot \mathrm{d}^{-1}\right)$, its contribution to the energy intake rose less than 4\%. This may be too little to account for the increased prevalence in obesity during the same period. Consistently, Sun and Empie [31] failed to find any association between obesity risk and usual sugar-sweetened beverage consumption in adults via analyzing databases of CSFII-1989-1991, CSFII-1994-1998, NHANES III, and combined NHANES 1999-2002 [31]. Animal studies show that carbohydrate-induced obesity is not unique to sweet-tasting sugars, but can also be produced by bland-tasting polysaccharides [32]. These studies as well as the present findings suggest that other carbohydrate categories which contribute more to total energy intake may be more important in examining the growing prevalence of obesity.

A more serious nutritional change related to the increase in intake of added sugars may be the apparent substitution of carbonated soft drink consumption for consumption of fluid milk [5]. Fluid milk was the principal nutritional contributor of energy intake for the 1-18 y age group in the 1970s. Its decreased contribution in the 1990s, and the increased contribution of carbonated soft drinks, may account for much of the decrease in total energy intake and percent energy intake from fat in that age group, as well as the decrease in intakes of calcium and lactose [6]. Overall, the effect of increased intake of added sugars, as it has replaced intake of intrinsic sugars such as lactose and fructose, has been to compromise the intake of more nutritious foods and impeded compliance with current dietary guidelines [6].

The amount and type of carbohydrate intake have also received significant attention with increasing prevalence of type 2 diabetes [33], which is highly associated with overweight. The switch from sucrose to high-fructose corn syrup (HFCS) as the sweetener, particularly in the US beverage industry since 1980s, has been suggested to explain the exponential growth of obesity in the U.S. [10] Gross et al. [33] reported that increased consumption of HFCS contributed to the increase of energy intakes and consequently to the prevalence of chronic diseases such as type 2 diabetes. Since fructose has higher sweet intensity than sucrose, theoretically the amount of HFCS to yield the same hedonic values would be less than that of sucrose. Clinical and epidemiological studies [10,34,35] have studied the effects of sucrose and fructose on incidence of obesity and other chronic diseases based on the 
estimates of consumption. Teff et al. [10], for example, estimated per capita consumption of added fructose being $81 \mathrm{~g} \cdot \mathrm{d}^{-1}$. The authors based their estimation of added fructose consumption on the average per capita FSD of 1997 [36], and then combined fructose from HFCS and fructose in the sucrose molecule [10]. In the present study of the NHANES III, we documented that American's fructose consumption is $30 \mathrm{~g} \cdot \mathrm{d}^{-1}$ and $27 \mathrm{~g} \cdot \mathrm{d}^{-1}$ for $1-18 \mathrm{y}$ and $19+\mathrm{y}$ sub-groups, respectively. Both groups consumed an average of $54 \mathrm{~g} \cdot \mathrm{d}^{-1}$ of sucrose.

Differences between the two studies are noteworthy $\left(28 \mathrm{~g} \cdot \mathrm{d}^{-1} v s .81 \mathrm{~g} \cdot \mathrm{d}^{-1}\right)$. We find it important to understand why, in order to assist future investigations in this important area of research. First, per capita disappearance data differ vastly from actual consumption [36]. According to the USDA report [24], loss of refined and beet sugars at retail, food service and consumer levels is estimated to be $31 \%$. Secondly, dietary intake data of an individual or population are reported as consumed in the form of food, beverage and supplements, not in metabolized forms. The USDA [20] and DHHS [17] provide dietary intake data of individual forms of simple sugars, i.e., glucose, fructose, galactose, lactose, sucrose, maltose, etc. If one was to estimate the total fructose intake by including fructose metabolized from sucrose, others may argue that glucose metabolized from maltose or starch should be considered in the glucose consumption estimates. Another consideration coming from the study of Duffey and Popkin [37] is that the concept of "total fructose" (including metabolized fructose from sucrose) might hide the truth that fructose consumption has been increasing, because their study showed that total fructose has changed relatively little compared with the change in free fructose and HFCS over the past two decades. American's per capita consumption of HFCS has increased along with glucose consumption in the U. S. However, the estimated fructose intake cited in the research papers has been overestimated, and might potentially mislead the nutritional science community.

Figure2. Comparison of the contribution (\%) of individual carbohydrates to the total carbohydrate intakes between the NHANES I and III by age subgroups.

$1-18$ years old

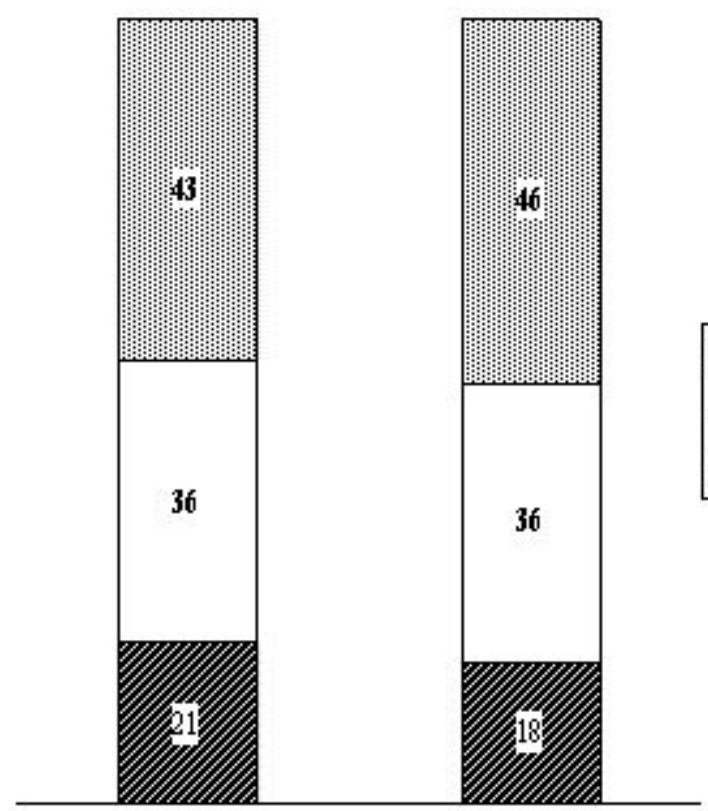

NHANES I
NHANES III

$19+$ years oll
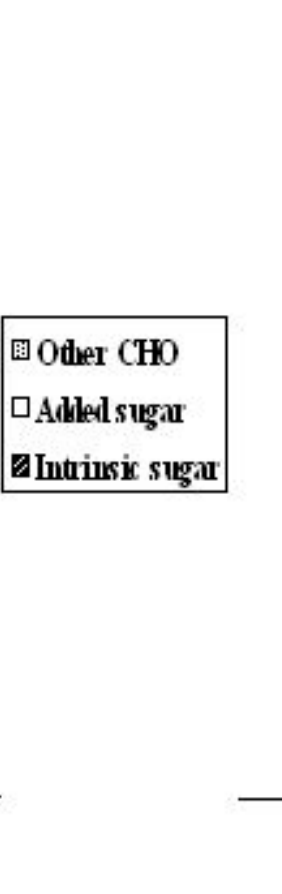

NHANES I

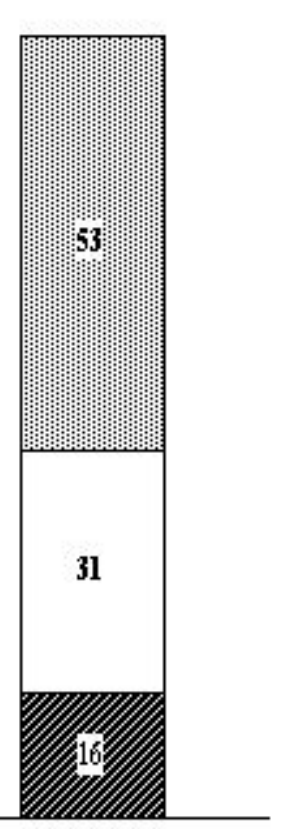

NHANES' III 
Our study has limitations. Firstly, since NHANES I included people aged 1-74 years, while NHANES III included people aged 1-90 years, the data for 19+ y subpopulation in the two datasets were not identical. NHANES I (1971-1975) and NHANES III (1988-1994) had different food codes to reflect changes in prevalent dietary behaviors, food commodities and lifestyles in the different time periods. The NHANES I database did not contain estimates of sugar intake levels. Using NHANES I and NHANES III to examine trends in sugar intakes, therefore, required us to develop a food code matching technique. Considering the long time span between the two surveys, the food composition under the same food name might have changed. For example, high-fructose corn syrup (HFCS) has been used as added sweetener, however, the percentage of HFCS of total sweetener has dramatically increased from $0.5 \%$ to $37.5 \%$, although total fructose (sum of free fructose and fructose contained in sucrose) availability changed only slightly over the same time period [37]. Although data for HFCS consumption are not available in 1970's, the results in Table 2 showed that our matching technique was effective and efficient in analyzing unknown sugar information in NHANES I.

\section{Conclusions}

The choice of database is critical in estimating food and nutrient intake. The technique we developed to match food codes in the NHANES datasets allows for their use as a source of reliable data on nutrient and energy intakes in general, and sugar intakes in particular, in the U.S. increased intakes of total and added sugars and carbohydrates have primarily accounted for the increase in energy intakes over the last two decades. The present study indicates that the overall increase in carbohydrate intake has by far exceeded the increase in intake of added sugars, and, thus, more specifically identifies the principal nutritional contribution associated with the rapid rise in obesity in the U.S. over the past three decades. In particular, although soft drink consumption is a major contributor to increased energy intake, the contribution to energy intake from "mixtures of mainly grain" has increased dramatically and is now the principal contributor to energy intake. Increased carbohydrate intake overall is mainly due to the increased availability and consumption of prepared, frozen and takeout meal combinations. Overall, this study points to the need for ongoing research on the specific nutritional contributors to total energy intake, and their potential contribution to increasing prevalence of obesity.

\section{References}

1. Mattews, R.; Pehrsson, P.; Farhat-Sabet, M. Sugar content of selected foods: individual and total sugars. In Home Economics Research Report No. 48; U.S. Department of Agriculture: Hyattsville, MD, USA, 1987.

2. Murphy, S.; Johnson, R. The scientific basis of recent US guidance on sugars intake. Am. J. Clin. Nutr. 2003, 78, 827S-833S.

3. World Health Organization. Diet, nutrition and the prevention of chronic diseases. In WHO Technical Report Series 916; Joint WHO/FAO Expert Consultation: Geneva, Switzerland, 2003.

4. Yang, E.J.; Chung, H.K.; Kim, W.Y.; Kerver, J.; Song, W.O. Carbohydrate intake is associated with diet quality and risk factors for cardiovascular disease in US adults: NHANES III. Am. J. Coll. Nutr. 2002, 22, 71-79. 
5. Park, Y.; Meier, E.; Bianchi, P.; Song, W. Trends in children's consumption of beverages: 1987 to 1998. Fam. Econ. Nutr. Rev. 2002, 14, 69-79.

6. Subar, A.; Krebs-Smith, S.; Cook, A.; Kahle, L.L. Dietary sources of nutrients among US children, 1989-1991. Pediatrics 1998, 102, 913-923.

7. Subar, A.; Krebs-Smith, S.; Cook, A.; Kahle, L.L. Dietary sources of nutrients among US adults, 1989-1991. J. Am. Diet. Assoc. 1998, 98, 537-547.

8. Cotton. P.; Subar. A.; Friday. J.; Cook, A. Dietary sources of nutrients among US adults, 1994-1996. J. Am. Diet. Assoc. 2004, 104, 921-930.

9. Cavadini. C.; Siega-Riz. A; Popkin, B. US adolescent food intake trends from 1965 to 1996. Arch. Dis. Child. 2000, 83, 18-24.

10. Teff. K.; Elliott. S.; Tschop. M.; Kieffer. T.; Rader. D.; Heiman. M.; Townsend. R.; Keim. N.; D'Alessio. D.; Have. P. Dietary fructose reduces circulating insulin and leptin, attenuates postprandial suppression of ghrelin, and increases triglycerides in women. J. Clin. Endocrinol. Metab. 2004, 89, 2963-2972.

11. Economic Research Service. Data: 2001 Food Consumption (per capita) Data System; U.S. Department of Agriculture: Washington, DC, USA, 2003.

12. National Center for Health Statistics. Prevalence of Overweight, Obesity and Extreme Obesity among Adults: United States, Trends 1976-80 through 2005-2006. CDC: Atlanta, GA, USA, 2008.

13. Berkey, C.; Rockett, H.; Field, A.; Gillman, M.; Colditz, G. Sugar-added beverages and adolescent weight change. Obes. Res. 2004, 12, 778-788.

14. Saris, W. Sugars, energy metabolism, and body weight control. Am. J. Clin. Nutr. 2003, 78, 850S-857S.

15. St-Onge, M.; Keller, K.; Heymsfield, S. Changes in childhood food consumption patterns: a cause for concern in light of increasing body weights. Am. J. Clin. Nutr. 2003, 78, 1068-1073.

16. National Center for Health Statistics. National Health and Nutrition Examination Survey, 19711975; 24-hour food consumption intake ages 1-74. Public use data tape documentation, tape number 4704. 1985; Available online : http://www.cdc.gov/nchs/nhanes.htm (Accessed on 29 July 2010).

17. National Center for Health Statistics. Third National Health and Nutrition Examination Survey (NHANES III) Reference Manuals and Reports [CD-ROM]; Center for Disease Control and Prevention: Hyattsville, MD, USA, 1996.

18. National Center for Health Statistics Third National Health and Nutrition Examination Survey, 1988-1994: NHANES III Individual Foods Data File from the Dietary Recall Documentation. Series 11, no. 2A [CD-ROM]; Center for Disease Control and Prevention: Hyattsville, MD, USA, 1998.

19. National Cancer Institute. Risk Factors Monitoring and Methods: documentation for the pyramid servings database for NHANES III.

20. U.S. Department of Agriculture Agricultural Research Service. CSFII 1994-1996, 1998 Data Set [CD-ROM]; U.S. Department of Agriculture: Beltsville, MD, USA, 2000.

21. Shah, B.; Barnwell, B.; Bieler, G. SUDAAN User's Manual. Release 8.0. Research Triangle Institute: Research Triangle Park, NC, USA, 2001. 
22. Harnack, L.J.; Jeffery, R.W.; Boutelle, K.N. Temporal trends in energy intake in the United States: an ecologic perspective. Am. J. Clin. Nutr. 2000, 71, 1478-84.

23. Barnard, N.D. Trends in food availability, 1909-2007. Am. J. Clin. Nutr. 2010, 91, 1530S-1536S.

24. Kantor, L. A Dietary Assessment of the U.S. Food Supply: Comparing Per Capita Food Consumption with Food Guide Pyramid Serving Recommendations. Agricultural Economics Report No. (AER772); Agricultural Economic. Food and Rural Economics Division, Economic Research Service, U.S. Department of Agriculture: Washington, DC, USA, 1998.

25. Agricultural Research Service. CSFII 1994-96, 1998 Data Set [CD-ROM]; Agricultural Research Service: Beltsville, MD, USA, 2000.

26. Johnson, R.K.; Frary, C. Choose beverages and foods to moderate your intake of sugars: The 2000 dietary guidelines for Americans-What's all the fuss about? J. Nutr. 2001, 131, 2766S-2771S.

27. Krebs-Smith, S.M. Choose beverages and foods to moderate your intake of sugars: measurement requires quantification. J. Nutr. 2001, 131, 527S-535S.

28. Institute of Medicine. Dietary Reference Intake for Energy, Carbohydrate, Fiber, Fat, Fatty Acids, Cholesterol, Protein, and Amino Acids. National Academy Press: Washington, DC, USA, 2002.

29. Harnack, L.; Stang, J.; Story, M. Soft drink consumption among US children and adolescents: nutritional consequences. J. Am. Diet. Assoc. 1999, 99, 436-441.

30. Lenders, C.M.; Hediger, M.L.; Scholl, T.O.; Khoo, C.-S.; Slap, G.B.; Stallings, V.A. Gestational age and infant size at birth are associated with dietary sugar intake among pregnant Adolescents. $J$. Nutr. 1997, 127, 1113-1117.

31. Sun, S.Z.; Empie, M.W. Lack of findings for the association between obesity risk and usual sugar-sweetened beverage consumption in adults-A primary analysis of databases of CSFII1989-1991, CSFII-1994-1998, NHANES III, and combined NHANES 1999-2002. Food Chem. Toxicol. 2007, 45, 1523-1536.

32. Sclafani, A.; Xenakis, S. Sucrose and polysaccharide induced obesity in the rat. Physiol. Behav. 1984, 32, 169-174.

33. Gross, L.; Li, L.; Ford, E.; Liu, S. Increased consumption of refined carbohydrates and the epidemic of type 2 diabetes in the United States: an ecologic assessment. Am. J. Clin. Nutr. 2004, 79, 774-779.

34. McDevitt, R.; Poppitt, S.; Murgatroyd, P.R.; Prentice, A.M. Macronutrient disposal during controlled overfeeding with glucose, fructose, sucrose, or fat in lean and obese women. Am. J. Clin. Nutr. 2000, 72, 369-377.

35. Bray, G.; Nielsen, S.; Popkin, B. Consumption of high-fructose corn syrup in beverages may play a role in the epidemic of obesity. Am. J. Clin. Nutr. 2004, 79, 537-543.

36. Economic Research Service. Food consumption: individual food consumption; U.S. Department of Agriculture: Washington, DC, USA, 2001.

37. Duffey, K.J.; Popkin, B.M. High-Fructose Corn Syrup: Is this what's for dinner? Am. J. Clin. Nutr. 2008, 88, 1722-1732. 
Appendix A. Comparisons of the order of food items which contribute to energy, carbohydrate and sugar intakes of the subjects aged 1-18 y between the NHANES I and III.

\begin{tabular}{|c|c|c|c|c|c|c|c|c|c|c|c|c|c|c|c|c|c|c|c|c|}
\hline \multirow{3}{*}{$\begin{array}{l}\text { Nutrients } \\
\text { Food items } \\
\text { Survey } \\
\end{array}$} & \multicolumn{6}{|c|}{ Macronutrients } & \multicolumn{14}{|c|}{ Individual sugars } \\
\hline & \multicolumn{2}{|c|}{ Energy } & \multicolumn{2}{|c|}{$\mathrm{CHO}$} & \multicolumn{2}{|c|}{$\begin{array}{l}\text { Total } \\
\text { sugar }\end{array}$} & \multicolumn{2}{|c|}{$\begin{array}{l}\text { Added } \\
\text { sugar }\end{array}$} & \multicolumn{2}{|c|}{ Glucose } & \multicolumn{2}{|c|}{ Fructose } & \multicolumn{2}{|c|}{ Galactose } & \multicolumn{2}{|c|}{ Sucrose } & \multicolumn{2}{|c|}{ Lactose } & \multicolumn{2}{|c|}{ Maltose } \\
\hline & $\mathrm{I}$ & III & I & III & I & III & I & III & $\mathrm{I}$ & III & I & III & $\mathrm{I}$ & III & $\mathrm{I}$ & III & I & III & $\mathrm{I}$ & III \\
\hline Apples & 31 & 35 & 19 & 23 & 15 & 18 & 19 & 24 & 8 & 14 & 4 & 5 & 28 & 36 & 14 & 21 & 33 & 47 & 20 & 25 \\
\hline Bananas & 38 & 38 & 28 & 29 & 24 & 22 & 46 & 51 & 14 & 15 & 19 & 15 & 29 & 37 & 18 & 20 & 34 & 42 & 41 & 49 \\
\hline Beer & 41 & 40 & 39 & 43 & 42 & 47 & 49 & 52 & 37 & 35 & 30 & 34 & 42 & 48 & 51 & 53 & 45 & 53 & 19 & 16 \\
\hline Cakes, pastries, pies & 5 & 7 & 4 & 7 & 3 & 5 & 3 & 5 & 11 & 12 & 17 & 21 & 23 & 25 & 1 & 1 & 11 & 12 & 10 & 11 \\
\hline Candies, sweets & 12 & 12 & 7 & 9 & 5 & 4 & 2 & 3 & 4 & 4 & 8 & 10 & 35 & 10 & 3 & 3 & 4 & 7 & 3 & 2 \\
\hline Cheese & 21 & 17 & 43 & 38 & 36 & 35 & 44 & 39 & 47 & 40 & 47 & 41 & 2 & 3 & 47 & 50 & 9 & 6 & 37 & 31 \\
\hline Citrus fruits & 36 & 44 & 25 & 35 & 17 & 28 & 37 & 36 & 13 & 27 & 11 & 20 & 25 & 33 & 15 & 27 & 30 & 44 & 16 & 21 \\
\hline Citrus juices & 24 & 23 & 15 & 16 & 8 & 7 & 24 & 22 & 2 & 3 & 2 & 4 & 26 & 34 & 20 & 19 & 31 & 45 & 35 & 48 \\
\hline Coffee & 53 & 53 & 51 & 51 & 52 & 52 & 47 & 45 & 52 & 50 & 52 & 52 & 52 & 40 & 52 & 48 & 52 & 48 & 52 & 50 \\
\hline Cookies & 7 & 13 & 6 & 14 & 9 & 12 & 8 & 8 & 24 & 21 & 21 & 23 & 45 & 51 & 4 & 8 & 13 & 17 & 27 & 17 \\
\hline Crackers & 29 & 27 & 23 & 27 & 34 & 29 & 22 & 21 & 33 & 37 & 32 & 36 & 46 & 21 & 27 & 23 & 49 & 39 & 24 & 35 \\
\hline Creams and cream substitutes & 46 & 45 & 47 & 48 & 40 & 41 & 30 & 31 & 35 & 45 & 43 & 48 & 14 & 28 & 36 & 40 & 16 & 16 & 23 & 27 \\
\hline Dark green vegetables & 48 & 47 & 46 & 46 & 44 & 43 & 53 & 49 & 34 & 38 & 33 & 35 & 48 & 24 & 40 & 42 & 50 & 19 & 51 & 43 \\
\hline Deep yellow vegetables & 43 & 46 & 36 & 39 & 29 & 36 & 28 & 30 & 31 & 33 & 28 & 33 & 49 & 52 & 26 & 32 & 51 & 31 & 8 & 13 \\
\hline Dried fruit & 47 & 49 & 42 & 42 & 35 & 34 & 42 & 44 & 26 & 23 & 23 & 19 & 27 & 35 & 46 & 46 & 32 & 46 & 40 & 39 \\
\hline Eggs & 16 & 24 & 41 & 44 & 30 & 38 & 41 & 43 & 21 & 26 & 48 & 42 & 16 & 13 & 45 & 43 & 12 & 13 & 38 & 32 \\
\hline Fats and oils & 8 & 18 & 44 & 41 & 33 & 32 & 15 & 20 & 29 & 30 & 24 & 24 & 32 & 15 & 37 & 33 & 14 & 14 & 42 & 33 \\
\hline Fish and shellfish & 28 & 31 & 38 & 37 & 48 & 51 & 32 & 33 & 41 & 46 & 39 & 45 & 9 & 26 & 43 & 49 & 48 & 41 & 49 & 53 \\
\hline Fluid milk & 1 & 2 & 2 & 5 & 1 & 2 & 34 & 47 & 46 & 51 & 41 & 50 & 7 & 18 & 35 & 51 & 1 & 1 & 28 & 42 \\
\hline Hot cereals & 33 & 32 & 27 & 28 & 38 & 30 & 38 & 38 & 28 & 36 & 27 & 30 & 19 & 30 & 34 & 25 & 24 & 15 & 17 & 28 \\
\hline Legumes & 26 & 28 & 20 & 24 & 27 & 37 & 20 & 25 & 27 & 32 & 25 & 31 & 10 & 7 & 23 & 31 & 25 & 29 & 33 & 26 \\
\hline Low-calorie carbonated soft drinks & 49 & 52 & 52 & 52 & 53 & 53 & 36 & 34 & 53 & 53 & 53 & 53 & 53 & 43 & 53 & 52 & 53 & 50 & 53 & 51 \\
\hline Low-calorie fruitades and drinks & 45 & 36 & 34 & 26 & 51 & 13 & 31 & 11 & 50 & 7 & 50 & 6 & 39 & 45 & 49 & 14 & 42 & 51 & 31 & 46 \\
\hline
\end{tabular}


Appendix A. Cont.

\begin{tabular}{|c|c|c|c|c|c|c|c|c|c|c|c|c|c|c|c|c|c|c|c|c|}
\hline \multirow{3}{*}{$\begin{array}{l}\text { Nutrients } \\
\text { Food items } \\
\text { Survey } \\
\end{array}$} & \multicolumn{6}{|c|}{ Macronutrients } & \multicolumn{14}{|c|}{ Individual sugars } \\
\hline & \multicolumn{2}{|c|}{ Energy } & \multicolumn{2}{|c|}{$\mathrm{CHO}$} & \multicolumn{2}{|c|}{$\begin{array}{c}\text { Total } \\
\text { sugar }\end{array}$} & \multicolumn{2}{|c|}{$\begin{array}{c}\text { Added } \\
\text { sugar }\end{array}$} & \multicolumn{2}{|c|}{ Glucose } & \multicolumn{2}{|c|}{ Fructose } & \multicolumn{2}{|c|}{ Galactose } & \multicolumn{2}{|c|}{ Sucrose } & \multicolumn{2}{|c|}{ Lactose } & \multicolumn{2}{|c|}{ Maltose } \\
\hline & $\mathrm{I}$ & III & $\mathrm{I}$ & III & $\mathrm{I}$ & III & $\mathrm{I}$ & III & $\mathrm{I}$ & III & $\mathrm{I}$ & III & $\mathrm{I}$ & III & $\mathrm{I}$ & III & $\mathrm{I}$ & III & $\mathrm{I}$ & III \\
\hline Meats (beef, pork, lamb, veal) & 3 & 8 & 48 & 47 & 39 & 48 & 51 & 41 & 45 & 47 & 29 & 46 & 1 & 19 & 33 & 41 & 23 & 38 & 47 & 44 \\
\hline Melons and berries & 40 & 43 & 31 & 36 & 20 & 26 & 29 & 26 & 20 & 25 & 10 & 18 & 30 & 38 & 16 & 24 & 35 & 33 & 12 & 22 \\
\hline Milk desserts & 10 & 16 & 11 & 18 & 6 & 10 & 7 & 7 & 10 & 17 & 22 & 22 & 15 & 5 & 7 & 9 & 2 & 3 & 1 & 3 \\
\hline Milk drinks & 18 & 11 & 17 & 10 & 13 & 6 & 12 & 9 & 38 & 19 & 38 & 27 & 13 & 6 & 11 & 6 & 3 & 2 & 22 & 7 \\
\hline Miscellaneous alcoholic beverages & 51 & 48 & 53 & 53 & 49 & 50 & 50 & 46 & 51 & 49 & 51 & 49 & 43 & 49 & 39 & 45 & 46 & 35 & 46 & 47 \\
\hline Miscellaneous nonalcoholic beverages & 42 & 51 & 33 & 49 & 11 & 44 & 10 & 32 & 15 & 44 & 15 & 38 & 40 & 46 & 8 & 36 & 43 & 26 & 45 & 41 \\
\hline Mixtures of mainly grain ${ }^{\mathrm{a}}$ & 6 & 1 & 9 & 2 & 21 & 17 & 16 & 16 & 16 & 9 & 14 & 9 & 4 & 1 & 24 & 18 & 10 & 4 & 9 & 9 \\
\hline Mixtures mainly meat, poultry, fish ${ }^{\mathrm{b}}$ & 14 & 6 & 22 & 12 & 26 & 20 & 21 & 15 & 23 & 13 & 20 & 12 & 11 & 9 & 28 & 17 & 8 & 8 & 26 & 14 \\
\hline Mixtures of mainly vegetables & 39 & 42 & 35 & 40 & 46 & 42 & 25 & 42 & 43 & 39 & 36 & 37 & 12 & 20 & 44 & 38 & 19 & 25 & 29 & 19 \\
\hline Noncitrus juices and nectars & 34 & 25 & 24 & 15 & 18 & 8 & 35 & 23 & 9 & 5 & 7 & 3 & 31 & 14 & 30 & 13 & 37 & 32 & 30 & 30 \\
\hline Nuts and seeds & 20 & 22 & 32 & 33 & 31 & 33 & 26 & 27 & 32 & 31 & 45 & 29 & 17 & 27 & 25 & 29 & 26 & 37 & 34 & 29 \\
\hline Organ meat, sausages, lunchmeat & 11 & 14 & 40 & 45 & 32 & 39 & 40 & 48 & 25 & 22 & 42 & 44 & 44 & 50 & 32 & 39 & 47 & 36 & 13 & 15 \\
\hline Other fruits and mixtures & 30 & 30 & 18 & 20 & 14 & 16 & 13 & 17 & 7 & 10 & 5 & 7 & 5 & 4 & 13 & 15 & 36 & 24 & 5 & 5 \\
\hline Other vegetables & 22 & 29 & 16 & 21 & 23 & 24 & 23 & 29 & 19 & 18 & 16 & 16 & 51 & 12 & 17 & 26 & 20 & 20 & 14 & 23 \\
\hline Pasta & 37 & 37 & 30 & 30 & 41 & 45 & 45 & 50 & 39 & 41 & 35 & 39 & 22 & 32 & 41 & 44 & 28 & 43 & 18 & 18 \\
\hline Popcorn, pretzel, corn chips & 27 & 19 & 26 & 19 & 37 & 31 & 27 & 28 & 30 & 28 & 31 & 28 & 24 & 23 & 31 & 30 & 29 & 27 & 15 & 12 \\
\hline Potatoes & 4 & 5 & 5 & 6 & 25 & 25 & 33 & 40 & 17 & 20 & 13 & 17 & 47 & 8 & 29 & 34 & 7 & 9 & 50 & 40 \\
\hline Poultry & 19 & 10 & 45 & 32 & 45 & 49 & 52 & 53 & 36 & 42 & 37 & 43 & 6 & 22 & 42 & 47 & 22 & 40 & 48 & 52 \\
\hline Quick breads, pancakes, fresh toast & 13 & 15 & 12 & 13 & 22 & 23 & 17 & 18 & 22 & 24 & 26 & 26 & 8 & 17 & 19 & 22 & 5 & 11 & 21 & 20 \\
\hline Regular carbonated soft drinks & 9 & 4 & 3 & 1 & 2 & 1 & 1 & 1 & 1 & 1 & 1 & 1 & 37 & 42 & 6 & 2 & 40 & 49 & 6 & 4 \\
\hline Regular fruitades and drinks & 17 & 20 & 10 & 8 & 4 & 3 & 4 & 2 & 3 & 2 & 3 & 2 & 38 & 44 & 5 & 5 & 41 & 28 & 44 & 36 \\
\hline Rice & 32 & 21 & 21 & 11 & 43 & 40 & 39 & 35 & 40 & 34 & 34 & 32 & 21 & 16 & 38 & 35 & 27 & 21 & 39 & 34 \\
\hline RTE cereals & 15 & 9 & 8 & 4 & 16 & 9 & 11 & 6 & 18 & 16 & 18 & 14 & 20 & 31 & 10 & 4 & 18 & 23 & 11 & 10 \\
\hline Sugar and sugar substitutes & 25 & 39 & 14 & 31 & 7 & 21 & 5 & 12 & 42 & 48 & 44 & 47 & 33 & 39 & 2 & 11 & 38 & 30 & 43 & 38 \\
\hline Syrups, jellies and desserts & 23 & 26 & 13 & 17 & 10 & 11 & 6 & 4 & 5 & 6 & 9 & 11 & 34 & 11 & 9 & 10 & 21 & 22 & 2 & 1 \\
\hline
\end{tabular}


Appendix A. Cont.

\begin{tabular}{|c|c|c|c|c|c|c|c|c|c|c|c|c|c|c|c|c|c|c|c|c|}
\hline Nutrients & & & $\mathrm{Mac1}$ & utrie & & & & & & & & & Indi & ual s & & & & & & \\
\hline \multirow{2}{*}{$\begin{array}{l}\text { Food items } \\
\text { Survey } \\
\end{array}$} & \multicolumn{2}{|c|}{ Energy } & \multicolumn{2}{|c|}{$\mathrm{CHO}$} & \multicolumn{2}{|c|}{ Total sugar } & \multicolumn{2}{|c|}{$\begin{array}{c}\text { Added } \\
\text { sugar }\end{array}$} & \multicolumn{2}{|c|}{ Glucose } & \multicolumn{2}{|c|}{ Fructose } & \multicolumn{2}{|c|}{ Galactose } & \multicolumn{2}{|c|}{ Sucrose } & \multicolumn{2}{|c|}{ Lactose } & \multicolumn{2}{|c|}{ Maltose } \\
\hline & I & III & I & III & I & III & I & III & I & III & I & III & I & III & I & III & I & III & I & III \\
\hline Tea & 44 & 33 & 37 & 22 & 28 & 15 & 18 & 13 & 49 & 52 & 49 & 51 & 36 & 41 & 22 & 7 & 39 & 34 & 25 & 45 \\
\hline Tomatoes & 35 & 34 & 29 & 25 & 19 & 19 & 14 & 14 & 12 & 11 & 12 & 13 & 50 & 53 & 21 & 16 & 15 & 18 & 7 & 6 \\
\hline Wine & 50 & 50 & 49 & 50 & 50 & 46 & 48 & 37 & 44 & 43 & 40 & 40 & 41 & 47 & 50 & 37 & 44 & 52 & 32 & 37 \\
\hline Yeast breads and rolls & 2 & 3 & 1 & 3 & 12 & 14 & 9 & 10 & 6 & 8 & 6 & 8 & 18 & 29 & 12 & 12 & 6 & 5 & 4 & 8 \\
\hline Yogurt & 52 & 41 & 50 & 34 & 47 & 27 & 43 & 19 & 48 & 29 & 46 & 25 & 3 & 2 & 48 & 28 & 17 & 10 & 36 & 24 \\
\hline
\end{tabular}

${ }^{\text {a }}$ Mixtures of mainly grain include mixtures having a grain product as a main ingredient, such as burritos, tacos, pizza, egg rolls, quiche, spaghetti with sauce, rice and pasta mixtures; frozen meals in which the main course is a grain mixture; noodle and rice soups; and baby-food macaroni and spaghetti mixtures.

${ }^{\mathrm{b}}$ Mixtures mainly meat, poultry, fish includes mixtures having meat, poultry, or fish as a main ingredient, such as chicken cacciatore; beef loaf; chili con carne; venison stew; hash; tuna salad; corn dog; chicken soup; frozen meals in which the main course is a meat, poultry, or fish item; meat, poultry, or fish sandwiches coded as a single item (for example, cheese burger on a bun); and baby-food meat and poultry mixtures. 
Appendix B. Comparisons of the order of food items which contribute to energy, carbohydrate and sugar intakes of the subjects aged 19+ y between the NHANES I and III

\begin{tabular}{|c|c|c|c|c|c|c|c|c|c|c|c|c|c|c|c|c|c|c|c|c|}
\hline \multirow{3}{*}{$\begin{array}{l}\text { Nutrients } \\
\text { Food items } \\
\text { Survey } \\
\end{array}$} & \multicolumn{8}{|c|}{ Macronutrients } & \multicolumn{12}{|c|}{ Individual sugars } \\
\hline & \multicolumn{2}{|c|}{ Energy } & \multicolumn{2}{|c|}{$\mathrm{CHO}$} & \multicolumn{2}{|c|}{$\begin{array}{l}\text { Total } \\
\text { sugar }\end{array}$} & \multicolumn{2}{|c|}{$\begin{array}{c}\text { Added } \\
\text { sugar }\end{array}$} & \multicolumn{2}{|c|}{ Glucose } & \multicolumn{2}{|c|}{ Fructose } & \multicolumn{2}{|c|}{ Galactose } & \multicolumn{2}{|c|}{ Sucrose } & \multicolumn{2}{|c|}{ Lactose } & \multicolumn{2}{|c|}{ Maltose } \\
\hline & $\mathrm{I}$ & III & $\mathrm{I}$ & III & $\mathrm{I}$ & III & $\mathrm{I}$ & III & $\mathrm{I}$ & III & $\mathrm{I}$ & III & $\mathrm{I}$ & III & $\mathrm{I}$ & III & $\mathrm{I}$ & III & $\mathrm{I}$ & III \\
\hline Apples & 35 & 43 & 22 & 29 & 13 & 19 & 22 & 32 & 10 & 17 & 3 & 4 & 30 & 37 & 18 & 22 & 34 & 44 & 22 & 28 \\
\hline Bananas & 44 & 36 & 29 & 23 & 25 & 18 & 46 & 51 & 19 & 9 & 18 & 14 & 31 & 38 & 22 & 13 & 35 & 42 & 42 & 52 \\
\hline Beer & 10 & 12 & 12 & 19 & 28 & 35 & 49 & 52 & 24 & 14 & 15 & 21 & 43 & 50 & 51 & 53 & 46 & 53 & 4 & 3 \\
\hline Cakes, pastries, pies & 4 & 5 & 3 & 5 & 4 & 2 & 3 & 2 & 11 & 15 & 14 & 18 & 25 & 21 & 2 & 1 & 9 & 12 & 10 & 12 \\
\hline Candies, sweets & 20 & 22 & 15 & 17 & 10 & 8 & 7 & 5 & 12 & 10 & 30 & 23 & 36 & 14 & 4 & 5 & 10 & 11 & 6 & 5 \\
\hline Cheese & 15 & 14 & 42 & 47 & 33 & 37 & 44 & 44 & 46 & 46 & 47 & 44 & 2 & 3 & 47 & 51 & 4 & 5 & 38 & 37 \\
\hline Citrus fruits & 36 & 49 & 23 & 40 & 15 & 29 & 35 & 27 & 13 & 28 & 12 & 22 & 27 & 34 & 13 & 26 & 31 & 46 & 17 & 25 \\
\hline Citrus juices & 21 & 28 & 9 & 15 & 5 & 7 & 25 & 47 & 2 & 2 & 2 & 2 & 28 & 35 & 20 & 20 & 32 & 47 & 36 & 50 \\
\hline Coffee & 45 & 41 & 51 & 32 & 52 & 47 & 47 & 28 & 53 & 48 & 52 & 52 & 52 & 42 & 52 & 37 & 52 & 21 & 52 & 32 \\
\hline Cookies & 19 & 18 & 11 & 16 & 12 & 12 & 9 & 10 & 27 & 26 & 23 & 27 & 46 & 52 & 5 & 6 & 16 & 19 & 29 & 20 \\
\hline Crackers & 29 & 31 & 25 & 26 & 38 & 38 & 24 & 23 & 36 & 41 & 34 & 42 & 47 & 25 & 29 & 29 & 49 & 40 & 27 & 34 \\
\hline Creams and cream substitutes & 32 & 37 & 35 & 44 & 30 & 31 & 14 & 20 & 25 & 31 & 43 & 43 & 16 & 30 & 37 & 40 & 5 & 9 & 8 & 11 \\
\hline Dark green vegetables & 50 & 45 & 46 & 43 & 45 & 44 & 53 & 49 & 35 & 39 & 32 & 33 & 49 & 20 & 39 & 41 & 50 & 17 & 51 & 45 \\
\hline Deep yellow vegetables & 47 & 48 & 34 & 37 & 32 & 30 & 30 & 33 & 32 & 35 & 29 & 30 & 50 & 29 & 24 & 24 & 51 & 37 & 9 & 8 \\
\hline Dried fruit & 51 & 51 & 41 & 46 & 36 & 34 & 38 & 45 & 23 & 22 & 21 & 19 & 29 & 36 & 40 & 47 & 33 & 48 & 41 & 44 \\
\hline Eggs & 12 & 19 & 43 & 45 & 31 & 36 & 42 & 41 & 14 & 25 & 48 & 38 & 18 & 12 & 46 & 42 & 12 & 14 & 39 & 30 \\
\hline Fats and oils & 5 & 9 & 44 & 38 & 35 & 28 & 15 & 16 & 28 & 24 & 20 & 20 & 13 & 13 & 34 & 30 & 14 & 15 & 30 & 26 \\
\hline Fish and shellfish & 23 & 23 & 40 & 34 & 49 & 51 & 32 & 34 & 40 & 47 & 36 & 45 & 8 & 22 & 43 & 49 & 48 & 43 & 49 & 51 \\
\hline Fluid milk & 3 & 8 & 5 & 10 & 2 & 3 & 36 & 43 & 47 & 51 & 44 & 50 & 1 & 5 & 41 & 46 & 1 & 1 & 33 & 38 \\
\hline Hot cereals & 41 & 40 & 31 & 31 & 41 & 46 & 40 & 46 & 33 & 44 & 31 & 41 & 21 & 31 & 36 & 38 & 23 & 18 & 18 & 31 \\
\hline Legumes & 24 & 25 & 21 & 21 & 34 & 32 & 21 & 22 & 30 & 34 & 26 & 31 & 9 & 8 & 25 & 25 & 26 & 25 & 31 & 27 \\
\hline Low-calorie carbonated soft drinks & 49 & 53 & 52 & 53 & 53 & 53 & 34 & 29 & 53 & 53 & 53 & 53 & 53 & 45 & 53 & 52 & 53 & 51 & 53 & 53 \\
\hline Low-calorie fruitades and drinks & 52 & 50 & 47 & 41 & 51 & 26 & 37 & 14 & 50 & 16 & 50 & 12 & 40 & 47 & 49 & 28 & 43 & 35 & 32 & 47 \\
\hline Meats (beef, pork, lamb, veal) & 1 & 4 & 49 & 50 & 39 & 50 & 51 & 42 & 45 & 50 & 25 & 48 & 3 & 17 & 32 & 44 & 24 & 41 & 47 & 48 \\
\hline Melons and berries & 42 & 47 & 28 & 35 & 18 & 23 & 26 & 26 & 16 & 20 & 9 & 15 & 32 & 39 & 14 & 18 & 36 & 36 & 13 & 22 \\
\hline
\end{tabular}


Appendix B. Cont.

\begin{tabular}{|c|c|c|c|c|c|c|c|c|c|c|c|c|c|c|c|c|c|c|c|c|}
\hline \multirow{3}{*}{$\begin{array}{l}\text { Nutrients } \\
\text { Food items } \\
\text { Survey }\end{array}$} & \multicolumn{8}{|c|}{ Macronutrients } & \multicolumn{12}{|c|}{ Individual sugars } \\
\hline & \multicolumn{2}{|c|}{ Energy } & \multicolumn{2}{|c|}{$\mathrm{CHO}$} & \multicolumn{2}{|c|}{$\begin{array}{l}\text { Total } \\
\text { sugar }\end{array}$} & \multicolumn{2}{|c|}{$\begin{array}{c}\text { Added } \\
\text { sugar }\end{array}$} & \multicolumn{2}{|c|}{ Glucose } & \multicolumn{2}{|c|}{ Fructose } & \multicolumn{2}{|c|}{ Galactose } & \multicolumn{2}{|c|}{ Sucrose } & \multicolumn{2}{|c|}{ Lactose } & \multicolumn{2}{|c|}{ Maltose } \\
\hline & $\mathrm{I}$ & III & $\mathrm{I}$ & III & $\mathrm{I}$ & III & $\mathrm{I}$ & III & $\mathrm{I}$ & III & $\mathrm{I}$ & III & $\mathrm{I}$ & III & $\mathrm{I}$ & III & $\mathrm{I}$ & III & I & III \\
\hline Milk desserts & 17 & 17 & 14 & 18 & 7 & 9 & 8 & 7 & 15 & 18 & 22 & 24 & 17 & 6 & 7 & 7 & 2 & 2 & 1 & 2 \\
\hline Milk drinks & 33 & 33 & 26 & 27 & 19 & 16 & 13 & 12 & 44 & 32 & 41 & 35 & 15 & 9 & 15 & 10 & 3 & 3 & 24 & 14 \\
\hline Miscellaneous alcoholic beverages & 22 & 30 & 53 & 48 & 21 & 33 & 50 & 25 & 51 & 30 & 51 & 25 & 44 & 51 & 11 & 31 & 47 & 28 & 46 & 24 \\
\hline Miscellaneous nonalcoholic beverages & 48 & 52 & 38 & 52 & 14 & 41 & 10 & 37 & 22 & 37 & 19 & 32 & 41 & 48 & 8 & 34 & 44 & 29 & 45 & 46 \\
\hline Mixtures of mainly grain ${ }^{\mathrm{a}}$ & 11 & 1 & 8 & 3 & 26 & 20 & 20 & 19 & 20 & 13 & 17 & 11 & 6 & 2 & 28 & 23 & 13 & 8 & 12 & 10 \\
\hline Mixtures mainly meat, poultry, fish ${ }^{\mathrm{b}}$ & 7 & 3 & 19 & 7 & 22 & 15 & 19 & 13 & 18 & 12 & 16 & 10 & 12 & 7 & 27 & 15 & 8 & 4 & 25 & 15 \\
\hline Mixtures of mainly vegetables & 43 & 46 & 36 & 42 & 46 & 48 & 27 & 39 & 39 & 42 & 35 & 39 & 11 & 23 & 38 & 45 & 18 & 22 & 34 & 39 \\
\hline Non-citrus juices and nectars & 40 & 44 & 27 & 30 & 20 & 21 & 29 & 31 & 9 & 11 & 8 & 5 & 33 & 40 & 26 & 27 & 38 & 49 & 28 & 35 \\
\hline Nuts and seeds & 27 & 24 & 37 & 39 & 40 & 39 & 33 & 38 & 37 & 38 & 45 & 36 & 19 & 27 & 31 & 32 & 27 & 39 & 35 & 36 \\
\hline Organ meat, sausages, lunchmeat & 8 & 13 & 45 & 51 & 37 & 43 & 39 & 48 & 26 & 27 & 42 & 47 & 45 & 28 & 33 & 43 & 25 & 34 & 15 & 19 \\
\hline Other fruits and mixtures & 30 & 34 & 18 & 24 & 11 & 13 & 11 & 21 & 6 & 6 & 5 & 6 & 7 & 4 & 12 & 14 & 37 & 32 & 5 & 6 \\
\hline Other vegetables & 18 & 20 & 10 & 13 & 16 & 17 & 23 & 24 & 8 & 8 & 10 & 8 & 14 & 11 & 16 & 16 & 20 & 20 & 16 & 21 \\
\hline Pasta & 39 & 35 & 30 & 28 & 48 & 49 & 45 & 50 & 43 & 43 & 38 & 40 & 24 & 33 & 45 & 48 & 29 & 45 & 19 & 23 \\
\hline Popcorn, pretzel, corn chips & 38 & 21 & 32 & 22 & 43 & 42 & 31 & 35 & 34 & 36 & 39 & 37 & 26 & 24 & 35 & 35 & 30 & 30 & 21 & 16 \\
\hline Potatoes & 6 & 6 & 4 & 4 & 24 & 27 & 28 & 36 & 17 & 21 & 13 & 17 & 48 & 16 & 30 & 33 & 11 & 10 & 50 & 40 \\
\hline Poultry & 16 & 10 & 48 & 36 & 47 & 52 & 52 & 53 & 38 & 45 & 33 & 46 & 5 & 19 & 44 & 50 & 22 & 38 & 48 & 49 \\
\hline Quick breads, pancakes, fresh toast & 13 & 11 & 7 & 9 & 23 & 25 & 18 & 18 & 21 & 23 & 28 & 28 & 10 & 18 & 21 & 17 & 6 & 13 & 23 & 18 \\
\hline Regular carbonated soft drinks & 9 & 7 & 2 & 2 & 1 & 1 & 1 & 1 & 1 & 1 & 1 & 1 & 38 & 44 & 3 & 4 & 41 & 50 & 7 & 4 \\
\hline Regular fruitades and drinks & 28 & 27 & 16 & 12 & 6 & 5 & 6 & 4 & 3 & 3 & 4 & 3 & 39 & 46 & 9 & 8 & 42 & 33 & 44 & 42 \\
\hline Rice & 31 & 15 & 20 & 6 & 50 & 45 & 41 & 40 & 42 & 40 & 37 & 34 & 23 & 10 & 42 & 39 & 28 & 26 & 40 & 43 \\
\hline RTE cereals & 26 & 16 & 17 & 8 & 27 & 14 & 16 & 11 & 29 & 19 & 24 & 16 & 22 & 32 & 19 & 9 & 19 & 23 & 14 & 13 \\
\hline Sugar and sugar substitutes & 14 & 29 & 6 & 14 & 3 & 6 & 2 & 3 & 41 & 49 & 40 & 49 & 34 & 41 & 1 & 3 & 39 & 16 & 43 & 33 \\
\hline Syrups, jellies and desserts & 25 & 32 & 13 & 20 & 8 & 11 & 4 & 6 & 5 & 5 & 11 & 13 & 35 & 15 & 6 & 11 & 21 & 27 & 2 & 1 \\
\hline Tea & 46 & 26 & 33 & 11 & 29 & 4 & 12 & 8 & 49 & 52 & 49 & 51 & 37 & 43 & 17 & 2 & 40 & 31 & 20 & 41 \\
\hline
\end{tabular}


Appendix B. Cont.

\begin{tabular}{|c|c|c|c|c|c|c|c|c|c|c|c|c|c|c|c|c|c|c|c|c|}
\hline \multirow{3}{*}{$\begin{array}{l}\text { Nutrients } \\
\text { Food items } \\
\text { Survey } \\
\end{array}$} & \multicolumn{8}{|c|}{ Macronutrients } & \multicolumn{12}{|c|}{ Individual sugars } \\
\hline & \multicolumn{2}{|c|}{ Energy } & \multicolumn{2}{|c|}{$\mathrm{CHO}$} & \multicolumn{2}{|c|}{$\begin{array}{l}\text { Total } \\
\text { sugar }\end{array}$} & \multicolumn{2}{|c|}{$\begin{array}{l}\text { Added } \\
\text { sugar }\end{array}$} & \multicolumn{2}{|c|}{ Glucose } & \multicolumn{2}{|c|}{ Fructose } & \multicolumn{2}{|c|}{ Galactose } & \multicolumn{2}{|c|}{ Sucrose } & \multicolumn{2}{|c|}{ Lactose } & \multicolumn{2}{|c|}{ Maltose } \\
\hline & $\mathrm{I}$ & III & $\mathrm{I}$ & III & I & III & $\mathrm{I}$ & III & $\mathrm{I}$ & III & $\mathrm{I}$ & III & $\mathrm{I}$ & III & $\mathrm{I}$ & III & $\mathrm{I}$ & III & $\mathrm{I}$ & III \\
\hline Tomatoes & 34 & 38 & 24 & 25 & 17 & 22 & 17 & 17 & 7 & 7 & 7 & 9 & 51 & 53 & 23 & 21 & 17 & 24 & 11 & 9 \\
\hline Wine & 37 & 39 & 39 & 49 & 42 & 40 & 48 & 30 & 31 & 33 & 27 & 29 & 42 & 49 & 50 & 36 & 45 & 52 & 26 & 29 \\
\hline Yeast breads and rolls & 2 & 2 & 1 & 1 & 9 & 10 & 5 & 9 & 4 & 4 & 6 & 7 & 20 & 26 & 10 & 12 & 7 & 6 & 3 & 7 \\
\hline Yogurt & 53 & 42 & 50 & 33 & 44 & 24 & 43 & 15 & 48 & 29 & 46 & 26 & 4 & 1 & 48 & 19 & 15 & 7 & 37 & 17 \\
\hline
\end{tabular}

${ }^{a}$ Mixtures of mainly grain include mixtures having a grain product as a main ingredient, such as burritos, tacos, pizza, egg rolls, quiche, spaghetti with sauce, rice and pasta mixtures; frozen meals in which the main course is a grain mixture; noodle and rice soups; and baby-food macaroni and spaghetti mixtures.

${ }^{\mathrm{b}}$ Mixtures mainly meat, poultry, fish includes mixtures having meat, poultry, or fish as a main ingredient, such as chicken cacciatore; beef loaf; chili con carne; venison stew; hash; tuna salad; corn dog; chicken soup; frozen meals in which the main course is a meat, poultry, or fish item; meat, poultry, or fish sandwiches coded as a single item (for example, cheese burger on a bun); and baby-food meat and poultry mixtures.

(C) 2010 by the authors; licensee MDPI, Basel, Switzerland. This article is an Open Access article distributed under the terms and conditions of the Creative Commons Attribution license (http://creativecommons.org/licenses/by/3.0/). 